\title{
Violence against Women and its Impact on Ecology: A Post-Jungian Perspective
}

\author{
Maysar Sarieddine*
}

Lebanese American University, Beirut, Lebanon

\begin{abstract}
Violence against women refers to any act or threat of violence that may result in physical, sexual, mental, or psychological harm to women, which is perpetrated based solely on their gender. Various movements such as feminist groups and equal rights groups have exerted much effort in seeking protection and justice for victims of violence against women, and in reducing cases of such violence through education, legislation, and social interventions. Such efforts include the creation of the Committee on the Elimination of Discrimination against Women and the Declaration on the Elimination of Violence against Women, the movements of various feminist groups across the globe, the establishment of women's shelters, and the passing of laws to protect women and punish offenders.
\end{abstract}

Keywords: Women; Violence

\section{Introduction}

Although there has been much social, legal, and international effort to eliminate discrimination and violence against women [1], the problem of violence against women continues to persist globally today. In the academe, much research has been conducted to measure $[2,3]$, understand [4], and seek solutions [5] for violence against women. Researchers have explored the issue of violence against women from different perspectives and disciplines, including education [6], political science $[7,8]$, anthropology $[9,10]$, sociology $[11,12]$, and psychology $[13,14]$. They traced the motivations behind violence against women, exploring social, cultural, and religious reasons. Some researchers have focused on analyzing and understanding the opinions and experiences of victims of violence, while others have focused on the perceptions of the perpetrators of such violence. Studies have also measured and analyzed the effects of violence, discrimination, and threats on the women's physiological, emotional, and psychological well-being [15]. Taking a different approach, I will utilize post-Jungian theories to describe and understand the effects of violence against women in the Middle East on the ecology of the region, and also to determine how the rehabilitation of nature and Mother Earth can be instigated through post-Jungian psychological constructs and theories.

\section{Violence against Women in the Middle East}

The oppression of women in the Middle East has been studied by a good number of researchers, and research has shown that violence against women is most prevalent in this specific region $[3,16]$. Based on empirical evidence collected through observation and in-depth interviews, and examined through thematic analysis, most researchers have indicated that the perpetration of violence against women is often culturally motivated $[17,18]$. This observation is conspicuous in the prevalence of violence against women in the Middle East. In this region, women are perceived as objects possessed by men, and they are certainly treated in this manner. Women in the region live their entire lives abiding by rules and commands set forth by the men in their lives, i.e., their fathers, brothers, and uncles before they are married, and their husbands, after they are wed $[3,17]$. The manner through which men exercise control over their women may be physical, emotional, sexual, economical, or psychological; nevertheless, all of these are considered abusive behavior and are within the definition of violence against women.
As mentioned, many academics have traced this pattern of behavior among men and women (i.e., men abusing women and women accepting inferiority to men) to be culturally, and thus also religiously, motivated [3,16-18]. Additionally, studies have also followed and analyzed the effects of such abuse and violence on women and their children [3], and how these women are able to cope with, and eventually break away from, such abuse [5]. However, recently, few studies have analyzed the parallel effects of such relationships with the natural environment or even the built environment $[19,20]$. As this patriarchal relationship between men and women have persisted for years, it may be postulated that the relationship consequently affected not only the persons related to, or living near, these men and women, but also the environment that has stood witness to such relationships.

\section{Jungian Approaches to Culture and Ecology}

Throughout his writings, Jung has expressed interest in science, specifically in biology and ecology [21]. He recounted his interest in biology in his biography Memories, Dreams, Reflections, published in 1963, wherein he recalled dreams of seeing animals or creatures, like the radiolarian [21]. Such dreams, at a young age, convinced Jung to pursue a future in science instead of humanities, as he was also interested in the arts. This is further evidenced in his publication Mind and Earth, wherein he described the poetic nature of the phrase "mind and earth" while establishing a correlation between these two elements. This relationship between mind and earth goes both ways. First, the more obvious relationship is that the mind influences a person's attitude or behavior towards the earth. And as religious doctrines have embedded in us the belief that life on earth is temporary, most people have disregarded and abused earth, and have misunderstood the earth and its soul [22]. The second relationship is that the earth has an

*Corresponding author: Maysar Sarieddine, Lebanese American University, Beirut, Lebanon, Tel: + 009613 333348; E-mail: maysar@gmail.com

Received: January 31, 2018; Accepted: February 15, 2018; Published: February 22, 2018

Citation: Sarieddine M (2018) Violence against Women and its Impact on Ecology: A Post-Jungian Perspective. Clin Exp Psychol 4:190. doi:10.4172/2471-2701.1000190

Copyright: ( $) 2018$ Sarieddine M. This is an open-access article distributed under the terms of the Creative Commons Attribution License, which permits unrestricted use, distribution, and reproduction in any medium, provided the original author and source are credited. 
unconscious effect on the mind, subtly influencing our thoughts and behaviors without knowing how or why [23]. Each place influences or impacts the mind in a way different from another place's influence, and Jung [23] went as far as indicating that land indigenizes migrants in a very mysterious way, probably because migrants remain connected to their natural race and culture while they adapt and feel belonging to the new environment they are in.

While the mind is often equated, or used interchangeably, with the psyche, the psyche should not be equated to consciousness because the psyche or the mind has a conscious portion and an unconscious portion. The archetypes, which are contained within the unconscious, are the hidden foundations of the conscious mind; and they represent a strong instinctive conservatism while being capable of instinctive adaptation [24]. It is through the unconscious that the psyche is connected or attached to nature, or in which its worldly link is most tangible. Thus, understanding the effect of the earth on the mind requires a closer look and examination of the nature and structure of the unconscious. Consequently, understanding a person's attitude towards nature and the world would necessitate an examination of that person's archetypes, specifically of the mother archetype [23]. In the unconscious, the mother archetype remains a powerful primordial image - despite us developing our own conscious individual image of the mother - that influences and determines our relations to women, society, and the world [23].

In one of his discourses, Jung remarked that "the earth has a spirit of her own, a beauty of her own and nature is not matter only, she is also spirit" [22], thereby asserting the correlation between Earth and women. D'Eaubonne [25] further emphasized this relationship in her book Le féminisme ou la mort, wherein she coined the term ecofeminism to describe the similarities of, and connects the exploitation, domination, and oppression of women with that of the environment. Ecofeminism is embodied in the similarities between women and nature, i.e. their biological status and reproductive capability; and some ecofeminists go as far as drawing connections between menstruation and moon cycles [19]. Additionally, ecofeminists indicated that the ways through which women become victims of violence and oppression are similar to the ways that nature is victimized $[19,20,25]$. Jung indicated that humans' victimization of nature also stems from how we refer to it, i.e., using the word matter has made objects and our ecological surrounding inhuman, thereby disabling us from truly relating to it; rather, we misunderstand and depreciate the Earth. This is much different from past practices when ancient men referred to it as the Great Mother, which attaches to it some great meaning and expression of profound human emotion towards the Earth and its contents [22]. Jung, therefore, advocated a return to the unconscious, which is primitive, spiritual, and artistic, in order for humans to better appreciate and relate with the Earth, the soul of the world, and all that is part of it.

\section{The Current Ecological Crisis}

It is well-discussed and documented in media, literature, international conferences, and political arenas that the world is currently facing an environmental crisis. This global problem includes an exponential increase in pollution, global warming, increased fossil fuel consumption, and depletion of natural resources. While this issue is often referred to as an environmental crisis, Tacey [13] indicated that doing so is a misuse of the term and an inadequate description of the underlying problem. More specifically, Tacey [13] referred to this issue as a crisis of human consciousness, because our habits, perceptions, and beliefs have fueled our failure to view the physical world and its contents or elements as sacred. We have taken for granted the world and all the natural elements because we do not perceive them as sacred, and only sacred things deserve and receive respect and care.

Tacey [13] traced the ecological crisis we currently face - the great biophysical depletion of nature and its resources - to our loss of awareness of how each natural element resulted from the hands of the creator, thus we began to treat the earth as a lifeless repository of resources that we use for personal gain and what we call innovation and globalization. In the same manner, he indicated that as soon as we regain consciousness of the sacredness of the Earth - as we recover a sense of the sacred - then the Earth will consequently recover from the crisis it faces and heal the damage it has incurred.

\section{The Relation Between Violence against Women and the Ecological Crisis}

In Jungian and post-Jungian writings, it is well-established that the Earth and its soul are feminine in nature: it is Mother Earth or the feminine Earth, and its contents are called matter, which was derived from the Latin mater, or mother. Accordingly in these writings, it is made evident that the issue of gender lies deep beneath the ecological problem we are currently facing. This was concisely forwarded by Tacey [13] as he correlated, "in the same way that patriarchy has devalued women and the human embodiment of the feminine, so has it devalued the earthly embodiment of the feminine". As stated in the previous section, the ecological crisis we currently face stemmed from a crisis of human consciousness, as we have failed to perceive and hold sacred the Earth and all its elements. In order to regain consciousness of the divine feminine, we must return to the soul of the world and recover this mythic personification of nature into our cultural awareness, which will ultimately change how we treat all of nature, i.e., with respect and care, not taking it for granted or treating it like an external, inhuman object. Some people have referred to the ecological crisis as the rape of nature $[13,26]$, which appears to be an appropriate metaphor as the abusive mentality shows a heroic-masculinist archetype - a patriarchal oppression - that has dominated and continued for a long time; and this patriarchal tendency is often influenced by culture and religion.

\section{The Influence of Religion on Violence against Women and Ecology}

All religions, in their most basic sense, categorize all things, whether tangible or abstract, as either divine/sacred or profane. In many religions, all things in nature are considered sacred, as the Earth and everything in it is believed to have been created by God, including all humans. Some religions and practices, such as Neopaganism and indigenous Native American and Latin American faith groups, hold the feminine to be sacred and often experience the sacred feminine in nature [27]. Such religious and spiritual practices reflect the interconnectivity of humans and nature, especially as feminine sacrality is often associated with those indigenous groups of people who produces and reproduces itself without human intervention and technology [28]. This is in contrast with, and has been overshadowed by, the male deities and imagery in Western and Abrahamic religions wherein the feminine is suppressed and marginalized [29]. Thus, more people across the globe have the tendency to take for granted Earth and all natural elements, and use its resources for personal gain. Additionally, it has been more ingrained in humans that life on earth is temporary, as the ultimate goal of all humans is to spend eternity in heaven. As stated earlier, this has led people to take for granted nature and all its elements. Thus, one influence of religion on how people treat the earth and all of nature is related to the promise of heaven and the belief that life on earth is temporary. 
Another way through which religion has influenced the ecological crisis is the lost image of God the father in our consciousness [13]. While millions of people still believe in one form or another of God, the current lifestyle of most people and the current practices of religion appear to be disengaged from the traditional sense of the word. As Tacey [13] indicated, God has been dead since the late nineteenth century, "and ever since the West has moved steadily away from a religious awareness that could make sense of the old deity." Indeed, Hathaway and Boff [30] asserted that people have been blinded by a systemic pathology that has caused the domination and destruction of the ecosystem [30]. People have abused the environment towards goals of wealth and power, limitless growth, and the desire for a global monoculture [30]. And although much effort and resources have been spent on informing people about the need to care for the environment and the planet, many people do not want to, or fear to, give up their way of life, even if it is necessary to save the planet.

In a similar way, religion has taught men that women are inferior to them and women are bred to obey their husbands. While Abrahamic religions may uphold the superiority of a male deity, men have perceived this as an absolute power that has led to a rampant abuse of women across the globe. This effect or influence of religion on men's propensity to perpetrate violence against women is also backed by academic research, as many studies $[3,31]$ have indicated that the pervasiveness of violence against women in the Middle East is greatly influenced by how the patriarchal religions sustain male dominance. In Abrahamic religions such as Islam and Christianity, women are perceived to be subordinate to men and that they should obey their husbands. This is put forward in religious texts, for example, "Men are in charge of women, because Allah hath made the one of them to excel the other, and because they spend of their property (for the support of women). So, good women are the obedient, guarding in secret that which Allah hath guarded. As for those from whom ye fear rebellion, admonish them and banish them to beds apart, and scourge them. Then if they obey you, seek not a way against them" (Quran, 4:34).

This is similarly expressed in the Christian Bible, "For the husband is the head of the wife, even as Christ is the head of the church: and he is the saviour of the body" (Ephesians 5:23, New International Version).

As men have come to abuse this power, it has led them to oppress women through various means, e.g. controlling how they spend money, what they eat, how they dress, where they go, and what they do. Additionally, men have also been reported to physically and sexually abuse their wives, claiming that their marriage has given them authority to take such actions as a means to assert their superiority and control their wives' actions. As religion also influences laws and legislations in most Middle Eastern countries, men, in essence, have the legal right to control their wives in whichever way they like. In many Arab countries, there are no laws to protect women and children from domestic violence. Women in Lebanon have been trying to get the parliament to pass such laws but many religious authorities continue to reject them for two reasons: first, it gives them less power in controlling people; and second, they use religious text to back their arguments. In this context, the interrelation of civil life and religion poses a big problem to movements towards the eradication of violence against women. Recent efforts, however, have been made towards eradicating such laws and deeming them as violating basic human rights, thereby giving women more liberty and control over their lives. Nonetheless, violence against women continues to be a major problem in Middle Eastern countries and across other regions.

\section{Summary and Reflection}

It is apparent in such writings that the ecological crisis we face is in large part similar to, and parallel with, the problem of violence against women around the world, as both issues stem from religious and cultural norms and beliefs. Jung himself, and those who furthered his analytical psychology school, have traced both issues - the ecological crisis and violence against women - to a psychological crises that needs to be addressed to truly eradicate the issue. First, violence against women has been shown to be an effect of upholding patriarchal values, which are largely furthered by religions and cultures, especially in the Middle East. Second, the ecological crisis we currently face was traced to be an effect of our disconnect with the earth, as religions have led us to believe that life on earth is temporary and thus we have disregarded or taken for granted the earth and all its elements.

Tacey [13] indicated that undoing the damage to the earth will take much more than working at purely external or economic levels on climate change and environmental issues. Indeed, a radical change in people's attitude towards nature is necessary if we are to adequately address the challenge posed by the environmental problem - the ecological crisis - we currently face, as this crisis has resulted from our belief, as we have been taught by Western philosophies and religion, that humans are superior to nature (Fairbanks, 2010). While attending to these issues externally is helpful, it is inadequate. As the ecological collapse has been traced as resulting from a crisis of human consciousness, it is believed that only a psychological rehabilitation, in this particular issue, a return of the soul of the world, will effectively address the issue. More specifically, such a movement would require an act of vision that will allow the so-called outside world - the inhuman earth - to reveal its interiority, or its soul [13]. Ideally, this act of visual perception will allow humans to recognize the soul of the Earth and inspire them to resacralize nature, i.e., to see nature and the Earth as a being that has a soul, which is sacred and needs to be respected.

In the same manner, humans must also approach the Earth and the soul of the world by presenting its interior, as Jung had postulated that it is through the unconscious and the archetypes within it that the psyche is connected to nature. In other words, a person's relation with, or treatment of, Mother Earth and all natural elements is dictated by his mother archetype within his unconscious, and it is through this archetype that the person may learn to appreciate and respect nature, and subsequently, women and society in general.

In addition to opening the unconscious and recovering the soul of the world, Hathaway and Boff [30] advocated that a change of lifestyle for all persons is necessary to save us and the Earth from the ecological crisis we currently face. While people developed and forwarded ways on how each person can help save the planet through science and technology (e.g. by recycling, lowering carbon footprint, and lessening fuel consumption), resuscitating the planet from the great extent of damage it has suffered would require "the development of a new paradigm, a new lens through which the Western mind can adjust its view of society, education and learning, citizenship, and the nature of human habitation on Earth" [30]. They perceive the current ecological crisis as more than a collection of mistakes and miscalculations that can be reversed or overridden; rather, they propose that what is needed is transformative learning. Similar to Tacey [13] who indicated that the current ecological crisis is really a crisis of human consciousness, Hathaway and Boff [30] utilized and redesigned transformative learning from an ecological perspective to address and understand the ecological crisis.

Prior to taking steps to develop a solution, we must first search for the wisdom to understand the nature of the crisis in order to change or revise our current understanding or consciousness of the issue. The next 
Citation: Sarieddine M (2018) Violence against Women and its Impact on Ecology: A Post-Jungian Perspective. Clin Exp Psychol 4:190. doi:10.4172/24712701.1000190

step in transformative learning is the revision of belief systems, which is in this case, the systems of religion and culture. And the third step is igniting behavioral or lifestyle changes. Taking these steps towards transforming perceptions and addressing a crisis are applicable to both the ecological crisis and the problem of the prevalence of violence against women. In both scenarios, it is necessary for people to first open their psyche and deepen their understanding of their unconscious, and how it has affected their actions and perceptions. Once they learn to understand better the relationship between each individual psyche and the society and Mother Earth, they can change their beliefs and the worldly rules and norms that used to control or influence the way they relate to women and the environment. Once these beliefs are revised or transformed, then each man can subsequently revise or transform the way he lives towards a more sustainable and peaceful future for all.

\section{Conclusion}

While the steps seem direct and clear, it is worth noting that inspiring people to connect with their inner unconscious selves and allowing such connection to change their beliefs are difficult, if not impossible. However, the extent of the ecological crisis and the prevalence of violence against women make it apparent that these issues necessitate psychological interventions for solutions to actually work and persist.

\section{References}

1. World Health Organization (2013) Global and regional estimates of violence against women: Prevalence and health effects of intimate partner violence and non-partner sexual violence.

2. Sörlin A, Öhman A, Ng N, Lindholm L (2012) Can the impact of gender equality on health be measured? A cross-sectional study comparing measures based on register data with individual survey-based data. BMC Public Health 12: 795.

3. Al-Badayneh D (2012) Violence against women in Jordan. J Fam Violence 27 369-379.

4. Mason C, Magnet S (2012) Surveillance studies and violence against women. Surveillance and Society 10: 105-118.

5. Hayati EN (2012) Mom, why don't you just look for a new good daddy? Women's lived experience in an abusive marriage. Journal of Educational, Health, and Community Psychology 1: 27-52.

6. Zeng J, Pang X, Rozelle S, Zhang L, Medina A (2014) Gender inequality in education in China: A meta-regression analysis. Contemporary Economic Policy 32: 474-491.

7. Parekh S (2011) Getting to the root of gender inequality: Structural injustice and political responsibility. Hypatia 26: 672-689.

8. Waylen G (2012) Gender matters in politics. Political Quarterly 83: 24-32.

9. Delcore HD (2007) New reflections on old questions in the anthropology of gender. Reviews in Anthropology 36: 109-130.
10. Shen Y (2011) China in the "post-patriarchal era." Chinese Sociology and Anthropology 43: 5-23.

11. Mandel H (2011) Rethinking the paradox: Tradeoffs in work-family policy and patterns of gender inequality. Community, Work, \& Family 14: 159-176.

12. Moore TS, Meiksins P, Root K (2013) Leaving science: Gender differences in career continuity following a job loss. Sociological Forum 28: 109-134.

13. Tacey D (2009) Edge of the sacred: Jung, psyche, Earth. Daimon, Einsiedeln Switzerland.

14. Toch $H$ (1992) Violent men: An inquiry into the psychology of violence. American Psychological Association, Washington, DC.

15. World Health Organization (2013b) Violence against women: Intimate partner and sexual violence against women. WHO, Geneva.

16. Ghanim D (2009) Gender and violence in the Middle East. Praeger, Westport, CT.

17. Marshall GA, Furr LA (2010) Factors that affect women's attitudes toward domestic violence in Turkey. Violence and Victims 25: 265-77.

18. Pease B, Flood M (2008) Rethinking the significance of attitudes in preventing men's violence against women. Australian Journal of Social Issues 43: 547561.

19. Ćorić D (2014) About ecofeminism (as a Part of Environmental Ethics). (English). Proceedings of Novi Sad Faculty of Law 47: 293-307.

20. Fairbanks SJ (2010) Environmental goodness and the challenge of American culture. Ethics and The Environment 15: 79-102.

21. Cambray J (2013) The red book: Entrances and exits. In: Kirsch T, Hogenson G (eds.), The red book: Reflections of C. G. Jung's Liber Novus. Routledge, New York, NY. pp: 36-53.

22. Jung CG (2002) The Earth has a soul: The nature writings of Jung CG. In Sabini M (ed.). North Atlantic Books, Berkeley, CA

23. Jung CG (1970) Mind and earth. The collected works of C. G. Jung. Princeton University Press, Princeton, NJ. pp: 29-49.

24. Jung CG (1970) On the nature of the psyche. The collected works of C. G. Jung. Princeton University Press, Princeton, NJ. pp: 159-234.

25. D'Eaubonne F (1974) Le féminisme ou la mort. P. Horay, Paris, France.

26. Faricy $R$ (2005) The exploitation of nature and Teilhard's ecotheology of love. Journal of Religion, Nature and the Environment 10: 181-195.

27. Saunders RA (2013) Pagan places: Towards a religiogeography of Neopaganism. Progress in Human Geography 37: 786-810.

28. Morton J (2013) Sacred shadows: The significance of the Black Madonnas International Journal of Religion and Spirituality in Society 2: 103-111.

29. Rushton K (2006) The new testament and "the feminine." Stimulus: The New Zealand Journal of Christian Thought and Practice 14: 12-16.

30. Hathaway M, Boff $L$ (2009) The tao of liberation: Exploring the ecology of transformation. Orbis Books, Maryknoll, NY.

31. Bradley T (2010) Religion as bridge between theory and practice in work on violence against women in Rajasthan. Journal of Gender Studies 19: 361-375. 